\section{Pré-construído e pré-discursos: possibilidades de análise a partir da teorização de Marie- Anne Paveau}

Pre-constructed and prediscourses: possibilities of analysis from the theorization by Marie-Anne Paveau

Rafaela Ramos da Silva NEVES (UNIR) rafaramoso612@gmail.com

Lucas Martins Gama KHALIL (UNIR) lucas.khalil@unir.br

Recebido em: 11 de abr. de 2019. Aceito em: 03 de out. de 2019.
NEVES, Rafaela Ramos da Silva; KHALIL, Lucas Martins Gama. Pré-construído e pré-discursos: possibilidades de análise a partir da teorização de Marie-Anne Paveau. Entrepalavras, Fortaleza, v. 9, n. 3, p. 226-243, set-dez/2019.

Resumo: Este artigo objetiva estabelecer relações de proximidade e de diferenciação entrea noção de pré-construído, formulada por Paul Henry e retomada por Michel Pêcheux na Análise de Discurso, ea noção de pré-discursos, conforme teorização relativamente mais recente de Marie-Anne Paveau. Considerando que essas duas noções teóricas se referem ao funcionamento de anterioridades discursivas, o que se propõe é um questionamento sobre os (novos?) caminhos de análise que podem se apresentar aos analistas de discurso a partir da abordagem dos pré-discursos. Com o objetivo de "testar" essas possibilidades de análise, a partefinal do artigo recorrea alguns enunciados que emergiram em manifestações de oposição ao governo de Dilma Rousseff no período após a sua reeleição (2014 - 2016), os quais foram retirados da página de compartilhamento de vídeos Youtube a partir do registro em vídeo feito pelos próprios manifestantes e pelos representantes das agências de notícia que cobriam os atos. Os enunciados coletados reforçam a especificidade da teoria de MarieAnne Paveau, já que denunciam os indícios de pré-discursos, assim como autorizam tecer possíveis aproximações entre o que propõem Pêcheux e Paveau no âmbito de temáticas que já se encontram devidamente exploradas no interior da Análise do Discurso.

Palavras-chave: Pré-construído. Prédiscursos. Anterioridades discursivas. Dilma Rousseff. 


\begin{abstract}
This article aims at establishing relations of proximity and differentiation between the pre-constructed notion formulated by Paul Henry and taken up by Michel Pêcheux in Discourse Analysis and the notion of pre-discourses, according to Marie-Anne Paveau's relatively recent theorization. Considering that these two theoretical notions refer to the functioning of discursive antecedents, what is proposed is a questioning about the (new?) ways of analysis that can present themselves to discourse analysts from the pre-discourse approach. In order to "test" these possibilities of analysis, the final part of the article refer to some statements that emerged in manifestations of opposition to Dilma Rousseff's government in the period after her re-election, which were taken from the page of sharing videos Youtube from the video record made by the protesters themselves and the representatives of news agencies that covered the acts. The statements collected reinforce the specificity of Marie-Anne's theory, since they denounce the vestige of pre-discourses, as well as authorize possible approximations between what they propose Pêcheux and Paveau in the context of themes that are already explored within the Discourse Analysis.
\end{abstract}

Keywords: Pre-constructed. Pre-discourse. Discursive antecedents. Dilma Rousseff.

\title{
Introdução
}

Em obra de 2006, a linguista Marie-Anne Paveau, elaborando a noção de pré-discursos, propõe que a Análise do Discurso passe a incorporar uma dimensão cognitiva no âmbito da reflexão sobre a produção dos sentidos nos discursos. Tendo em vista que o tema das anterioridades não se trata de algo novo para a Análise do Discurso, este artigo objetiva estabelecer relações teóricas entre os "pré-discursos" e o conceito de pré-construído, formulado por Paul Henry em meados da década de 1970 e também consolidado na Análise do Discurso francesa por Michel Pêcheux. Não se pretende realizar uma apresentação geral da obra dos três autores mencionados, mas discutir possibilidades de análise que se apresentariam aos analistas do discurso a partir da consideração da proposta de Paveau ([2006]/2013) e o modo como esses procedimentos analíticos se diferenciariam, ou não, do que já é praticado na Análise do Discurso, especificamente no que concerne às anterioridades dos enunciados.

A relevância da reflexão proposta, portanto, justifica-se pelo fato de a teoria de Paveau (2013) ser relativamente recente, o que faz com que sejam escassos os estudos discursivos pautados em novas possibilidades de análise em que se atrela cognição e discurso, como forma, sobretudo, de se pensar a respeito da problemática em torno das anterioridades discursivas.

O artigo contém três seções, além das considerações finais. Na primeira delas, o conceito de pré-construído é apresentado, com fundamentação em textos de Paul Henry e Michel Pêcheux, este último 
v. 9 (3)

226-243

set-dez

2019

considerado o fundador da Análise do Discurso francesa. A seção subsequente, por sua vez, dedica-se a uma introdução sobre como Marie-Anne Paveau concebe os pré-discursos e como ela os diferencia do pré-construído. Na terceira seção, algumas análises são esboçadas a fim de que possam ilustrar e sintetizar as especificidades das perspectivas teóricas em questão; recorre-se a um corpus proveniente de pesquisa, em andamento, sobre manifestações de oposição ao governo Dilma Rousseff após sua reeleição à presidência do Brasil (2014 - 2016), em que se verifica, por meio das produções discursivas pró-impeachment, a evocação a enunciados cuja carga semântica, histórica e ideológica se insere em momentos que seriam anteriores ao contexto das manifestações em si. Soma-se a isso, também, o fato de que, diferentemente do que se observou na materialidade discursiva dos grupos pró-Dilma, há evocação em larga escala de dados pré-discursivos por parte dos grupos que se opunham radicalmente à Dilma Rousseff.

A metodologia empregada para a constituição do corpus seguiu a esteira de Paveau (2013), uma vez que a autora propõe dois caminhos de análise: o primeiro integraria o que a autora chama de "paradigma léxico-fraseológico" (PAVEAU, 2013, p. 38), em que se parte das produções verbais em si em busca de seus anteriores; o segundo, por outro lado, insere-se em um paradigma perceptivo-cognitivo, em que se assume previamente a existência de pré-discursos e se objetiva encontrar os vestígios destes na materialidade linguageira dos sujeitos. Nosso artigo situa-se no segundo eixo e coletou os enunciados que serviram como base de análise no site de compartilhamento de vídeos Youtube, a partir do registro em vídeo feito pelos repórteres de diferentes agências de notícia (IG, Estadão, O Globo, entre outros) e pelos próprios manifestantes que participavam dos atos pró-impeachment. Também foram encontrados possíveis indícios de pré-discursos na seção reservada aos comentários nesse mesmo sítio.

\section{O conceito de pré-construído em Paul Henry e Michel Pêcheux}

Um texto fundamental para a gênese do conceito de préconstruído na Análise do Discurso, publicado em 1975 por Paul Henry, intitula-se Construções relativas e articulações discursivas. Nesse texto, antes de propor o conceito de pré-construído, o teórico empreende uma reflexão sobre a tradicional distinção entre orações relativas determinativas e relativas apositivas (ou explicativas). Para muitas das gramáticas, como 
a de Port-Royal, do século XVII, as relativas determinativas dependeriam da necessidade de identificação prática em uma "ordem das coisas" ou "do pensamento" (função designativa/referencial). Por exemplo, em o homem que roubou o carro foi preso, a relativa identificaria um ser em questão frente a outros possíveis homens. Já as relativas explicativas, apesar de introduzirem uma característica sobre o que está em questão no discurso, não funcionariam da mesma forma, tendo em vista que uma "ordem do discurso" poderia ser concebida independentemente de uma "ordem das coisas" ou da necessidade de identificação prática. É o que ocorreria, por exemplo, em "o homem, que é um animal, cresce e morre". Henry, no contexto dessa explanação, remete novamente à Gramática de PortRoyal, especificamente, dessa vez, à distinção entre nomes substantivos (que subsistiriam por eles mesmos) e nomes adjetivos (que significariam as substâncias, juntando-se a outros nomes). Essa distinção, como a que se realiza entre relativas determinativas e explicativas, suscita uma indagação fundamental à reflexão de Henry: o que subsiste por si mesmo no discurso? Uma interação, à primeira vista, inequívoca entre as ordens "das coisas" e "do discurso" não possibilitaria esse questionamento.

Ao abordar o modo como Noam Chomsky lida com a noção de referência na teoria gerativa, Henry enxerga um "retorno às fontes" por parte do linguista norte-americano, uma vez que se mantém a ideia de autonomia referencial (para a categoria dos substantivos, por exemplo). Voltando à questão das relativas, justamente por se considerar a possibilidade de "autonomia referencial" na língua, a aplicação da noção de referência funcionaria a partir desta distinção básica: a referência do antecedente da restritiva depende da relativa, enquanto a referência do antecedente da explicativa é independente da relativa.

Analisando as sentenças "um cachorro, o animal, é um carnívoro" (que soa estranha, segundo o linguista francês) e "um cachorro, o animal, me mordeu", Henry afirma que, apesar da semelhança sintática, a diferença entre as duas reside no fato de que um carnívoro não identificaria, a princípio, um cachorro determinado, como em me mordeu. Na segunda, é possível interpretar que o cachorro é chamado de animal pelo ato da mordida (o animal do cachorro me mordeu), e não por ser classificado propriamente como animal; isso ajudaria a explicar a estranheza do primeiro exemplo deste parágrafo (*o animal de um/do cachorro é um carnívoro). Com esses e outros exemplos, Henry (1990) conclui que mesmo as propriedades dos substantivos parecem ser propriedades contextuais e não intrínsecas 
V. 9 (3)

$226-243$ set-dez 2019

dessas unidades. "A noção de autonomia referencial concebida como uma característica de algumas categorias de unidades lexicais perde grande parte de seu valor explicativo" (HENRY, 1990, p.51). Começase a conceber o caráter referencial ou não referencial de uma unidade não como característica dessa unidade, mas como "[...] um efeito de sentido onde intervém conjuntamente a sintaxe e fatores semânticos" (HENRY, 1990, p. 51).

Recorrendo a um texto em que Michel Pêcheux e Catherine Fuchs discutem a relação de paráfrase como constitutiva dos enunciados que se relacionam a uma determinada formação discursiva, Henry levanta a hipótese de que a referencialidade é um efeito de sentido produzido pela possibilidade de substituição. Nas palavras do autor:

É a substituibilidade da unidade num discurso dado que lhe confere nesse discurso um caráter referencial e não o fato de que se possa definir, fora de contexto, a classe de seres suscetíveis de serem designados por esta unidade (HENRY, 1990, p. 52).

Deve-se, portanto, abandonar uma concepção de determinação baseada na noção de classe de seres designados por um substantivo definido fora de todo contexto.

Na parte final de seu artigo, Henry propõe abordar os mecanismos sintáticos enquanto efeitos de sentido da sintaxe, visto que ela é uma das manifestações do que se denomina "autonomia relativa da língua". Todo discurso, de acordo com o autor, é duplamente determinado, de um lado pelas formações ideológicas que relacionam esses discursos a formações discursivas, e de outro pela autonomia relativa da língua: "Se o discurso fosse inteiramente determinado em sua produção e interpretação pela língua, não haveria lugar para a noção de paráfrase discursiva" (HENRY, 1990, p. 59). Desenvolvendo essa teorização, Henry introduz a noção de "saturação", relacionada à delimitação de formulações que, em condições de produção e de interpretação dadas, podem entrar em relação de paráfrase discursiva:

É possível então que uma formulação possa parecer saturada como se sua saturação estivesse ligada a uma relação intrassequencial quando, na realidade, face à autonomia relativa da língua, é uma relação inter-sequencial que necessariamente se dá. Isto produz o efeito subjetivo de anterioridade, de implicitamente admitido etc. que designamos alhures de "préconstruído" (HENRY, 1990, p. 61). 
Conforme explica Henry (1990), a relação inter-sequencial, na relativa determinativa, é "apagada", por assim dizer, pela relação intrassequencial; em outras palavras, o mecanismo determinativo apresenta uma relação inter-sequencial como se fosse uma relação intrassequencial, a partir do efeito de implicitamente admitido característico do pré-construído. Vale destacar que esse efeito tem origem na ilusão de que o sujeito é a fonte do seu próprio dizer. Já na relativa explicativa, a relação inter-sequencial parece não ser apagada (a relação entre o antecedente e a relativa pode dizer respeito à ordem das evidências gerais, propriedades da natureza, por exemplo); admitese o efeito de um enunciado que efetivamente viria de "outro lugar". O autor conclui que não há como distinguir os dois funcionamentos de um ponto de vista estritamente sintático; é do ponto de vista discursivo que se poderia estabelecer uma diferenciação.

O conceito de pré-construído, apresentado no final do artigo de Paul Henry, repercute na obra Semântica e Discurso, de Michel Pêcheux. Nela, o autor realiza diversas críticas ao que chama de "evidências" no âmbito da Semântica. "A evidência diz: as palavras têm um sentido porque têm um sentido, e os sujeitos são sujeitos porque são sujeitos" (PÊCHEUX, 1997, p. 31). Substância x acidente, necessidade x contingência, objetividade $\mathrm{x}$ subjetividade são pares que, de acordo com o teórico, atravessam a história da Linguística, sobretudo em abordagens formalistas-logicistas, ajudando a explicar fenômenos como as relativas. Na Lógica de PortRoyal, recorre-se à "ordem das essências" para justificar a distinção entre determinativas e explicativas: a determinativa diz respeito exclusivamente à ordem do ser, o mundo das essências, fora de toda adjunção do pensamento; já a explicativa intervém como uma incidência do pensamento sobre a ordem das essências. Pêcheux, questionando as evidências dos sentidos, adverte que, em um domínio específico, como o da moral, a frase "Os homens que fogem são covardes" geraria inúmeros problemas (acerca da relação entre extensão e compreensão, da distinção entre propriedades essenciais e contingentes, da natureza do vínculo que une as propriedades fugir e ser covarde etc.). Segundo o teórico, existiria, tacitamente, uma pretensão idealista de se chegar ao conjunto de enunciados fixos e unívocos que recobrissem o conjunto da realidade.

Acerca da Linguística formal do século XX, Pêcheux (1997, p. 60) afirma que o corte estrutural e seus desdobramentos determinam "[...] paradoxalmente um reforço das ilusões substancialistas e subjetivistas no domínio da Semântica, sob a forma do par ideológico 
v. 9 (3)

226-243

set-dez

2019

criatividade/sistema". Esse reforço, segundo o autor, acaba relegando a questão do sentido a um segundo plano. É por isso que, ao propor o quadro teórico da Análise do Discurso, Pêcheux enfatiza que todo processo discursivo se inscreve numa relação ideológica de classes, estando o sentido submetido às restrições das formações discursivas.

Antes de formular a sua concepção de pré-construído, Pêcheux inicia um dos capítulos de Semântica e Discurso discorrendo sobre um exemplo de Gottlob Frege: "Aquele que descobriu a forma elíptica das órbitas planetárias morreu na miséria" (apud PÊCHEUX, 1997, p.95), em que se denota o cientista Kepler. De acordo com Frege, se a proposição em seu todo é aceita como verdadeira, não se pode negar a sua subordinada; além disso, a pressuposição de que Kepler designa algo vale tanto para a afirmação quanto para uma eventual afirmação oposta. Frege sugere, então, que o funcionamento da língua (nesse caso, a relação entre a oração principal e a subordinada relativa) induz a uma "ilusão", resultado de "armadilhas" de uma língua natural, falhas essas que poderiam desaparecer, segundo o teórico alemão, em uma língua artificial bem elaborada. Qual a relação de sentido entre as orações? O que elas teriam a ver entre si? Pêcheux lança a hipótese de uma perspectiva religiosa para a qual a miséria seria a contraparte do gênio, um castigo ao conhecimento. A perspectiva de Frege não se propõe a investigar esse tipo de relação, mas uma reflexão acerca dos efeitos de sentido, na Análise do Discurso, demanda questionar aspectos como a referencialidade das expressões.

Explorando um exemplo análogo ao de Frege, Pêcheux indaga se é desprovida de sentido uma frase como "aquele que salvou o mundo morrendo na cruz nunca existiu". Mesmo que a frase, à primeira vista, soe paradoxal, o autor sugere que ela poderia ser enunciada, por exemplo, no discurso do ateísmo militante. É no decorrer da reflexão sobre as relativas que Pêcheux (1997) esboça um questionamento fundamental à conceituação do pré-construído: "Não deveríamos [...] considerar que há separação, distância ou discrepância na frase entre o que é pensado antes, em outro lugar ou independentemente, e o que está contido na afirmação global da frase?" (PÊCHEUX, 1997, p.99). Para responder a isso, Pêcheux recorre ao texto de Henry, já abordado por este artigo, lembrando que o pré-construído designa uma construção que se encaixa sintaticamente ao enunciado, mas que soa ao sujeito como se fosse independente em relação a ele, funcionando como um sempre-já-lá, "[...] o impensado de seu pensamento" (PÊCHEUX, 1997, p. 102). 
"O Jesus Cristo dos cristãos" é outro exemplo formulado por Pêcheux (1997) em seu questionamento acerca das referencialidades supostamente inequívocas. Segundo o teórico, todo "conteúdo do pensamento", por assim dizer, existiria na linguagem sob a forma do discursivo. O caráter material do sentido, para além de sua evidencialidade, depende constitutivamente do que Pêcheux (1997) denomina "o todo complexo das formações ideológicas" e tal dependência é especificada pelo autor a partir de duas teses: 1) o sentido de uma palavra, expressão ou proposição não existe em si mesmo, estando submetido às restrições de uma formação discursiva; 2) "toda formação discursiva dissimula, pela transparência do sentido que nela se constitui, sua dependência com respeito ao todo complexo com dominante das formações discursivas, intrincado no complexo das formações ideológicas" (PÊCHEUX, 1997, p. 162). Após enunciar as teses, o teórico apresenta o conceito de interdiscurso - todo complexo com dominante das formações discursivas, submetido à lei de desigualdade, contradição, subordinação - e diferencia os dois elementos de seu funcionamento, pré-construído e articulação:

O pré-construído corresponde ao sempre-já-aí da interpelação ideológica que fornece-impõe a "realidade" e seu "sentido" sob a forma da universalidade (o "mundo das coisas"), ao passo que a articulação constitui o sujeito em sua relação com o sentido, de modo que ela representa, no interdiscurso, aquilo que determina a dominação da forma-sujeito (PÊCHEUX, 1997, p. 164).

Os elementos do interdiscurso, como se observa em Pêcheux (1997), constituem-se complementarmente, na medida em que a articulação, ao linearizar (ou sintagmatizar) o interdiscurso no eixo do intradiscurso põe em conexão aquilo que o pré-construído fornece como "matéria-prima", por assim dizer. O autor ainda esclarece que a articulação está em contato direto com o discurso-transverso - que funciona a partir de relações como parte-todo, causa-efeito, sintoma-diagnóstico etc. -, pois é com a articulação, e seus mecanismos de linearização, que o "fio do discurso" é garantido ao intradiscurso, que dissimula em seu interior o interdiscurso como se este já estivesse na origem de sua "coerência". O pré-construído, continua Pêcheux (1997), apresenta-se ao sujeito como "aquilo que todo mundo sabe" - identificação com o sujeito universal - e, ao mesmo tempo, aquilo que todos podem entender diante das "evidências" de um contexto situacional; já a articulação corresponde, na linearização, ao "como dissemos" (que evoca o próprio intradiscurso), ao "como todo mundo sabe" (que remete ao sujeito universal) e ao "como todo mundo pode ver" (que remete à evidencialidade de dado contexto situacional). 
v. 9 (3)

226-243

set-dez

2019

\title{
Marie-Anne Paveau, os pré-discursos e o pré-construído
}

Compreender a noção de Paveau (2013) a respeito dos prédiscursos envolve, inevitavelmente, levar em consideração o entendimento da linguista sobre o conceito de discurso e o impacto que os pré-discursos, segundo a autora, desempenhariam na produção e na interpretação discursivas. Ainda que, em Os pré-discursos: sentido, memória e cognição, não haja uma definição precisa de discurso, ao afirmar que:

\begin{abstract}
Pretendo, de fato, debruçar-me sobre o problema da 'caixa negra' das informações prévias que informam os discursos e, sobretudo, sobre o ponto de articulação entre estes dados anteriores e as produções verbais. Em outras palavras, ao se admitir que os discursos se apoiam em saberes e crenças partilhadas, a natureza deste apoio resta ainda um pouco misteriosa (PAVEAU, 2013, p. 12, [grifos nossos]).
\end{abstract}

A autora sugere que o discurso se situa em um nível entre a articulação da materialidade linguística e dados anteriores que seriam evocados no momento da produção discursiva em si. Além disso, Paveau (2013) supõe que tais anterioridades não se limitam à questão ideológica; são, na verdade, aspectos mais amplos que envolvem o conhecimento enciclopédico, a dimensão cultural e as crenças partilhadas entre os sujeitos (PAVEAU, 2013).

Para investigar o processo que leva à emersão desses prédiscursos, Paveau (2013) considera as hipóteses da cognição distribuída. Por isso, a autora argumenta que os pré-discursos são quadros pré-discursivos: elementos que funcionam à semelhança dos esquemas mentais, agindo, portanto, nos processos de construção de conhecimento e tornando possível o convívio em sociedade. Nesse passo, os quadros pré-discursivos são coletivos e constituem o que devemos falar e como devemos falar.

Entretanto, a autora argumenta que os pré-discursos não se restringem ao nível sintático, e que a investigação do analista deve atuar no sentido de reconhecer diversos sinais, indícios que os pré-discursos deixam na materialidade linguageira dos sujeitos. Sendo assim, o estatuto consolidado da noção de pré-construído na $\mathrm{AD}$ demanda que a autora teça as possíveis aproximações e/ou distanciamentos entre as duas teorias, o que vem acompanhado de uma revisão teórica em torno do conceito pecheuxtiano.

Paveau (2013, p. 72) ressalta que o pré-construído se manifesta indiretamente por meio de "estruturas sintáticas particulares" (construções relativas determinativas, nominalização, dentre outras formas), permitindo que o analista do discurso tenha uma melhor visualização linguística do fenômeno e contribuindo para que, pelo 
menos do ponto de vista linguístico, a noção do pré-construído seja mais profícua. No caso dos pré-discursos, algo semelhante não se verifica, pois estes se encontram relacionados a fatores cujas dimensões não estão circunscritas ao funcionamento linguístico em si (como conhecimentos de ordem enciclopédica). Porém, para a autora, o aspecto mais amplo dos pré-discursos viabiliza, diferentemente do que ocorre com a hipótese do pré-construído, outros níveis de análise linguística, como veremos na seção destinada à análise do corpus.

A autora destaca que o pré-construído se manifesta no intradiscurso por meio de sua natureza de efeito. Ainda que tal característica do pré-construído seja de suma importância - segundo a autora, o termo efeito indica a filiação filosófica do termo, afinal remete à ideia de efeito de evidência conforme o marxismo althusseriano, pois Louis Althusser (1970) entende que o efeito de evidência é resultado do assujeitamento ideológico -, esse aspecto, segundo a linguista, teria sido relegado ao segundo plano, enquanto que a dimensão sintática do discurso acabou por dominar grande parte das atenções analíticas.

Além de sua natureza de efeito, o pré-construído também apresenta o caráter de universalidade, conforme mencionado anteriormente neste artigo. Para Paveau (2013), isso demonstra como o pré-construído se reveste de um alcance coletivo, fazendo com que a noção, pelo menos no que tange a esse ponto, resulte em contribuições para a sua teoria dos pré-discursos. É importante notar ainda que a linguista advoga a favor de uma imaterialidade como característica do conceito de pré-construído:

As consequências teóricas são, efetivamente, importantes: o fato de que o pré-construído seja um efeito implica uma imaterialidade do fenômeno, o que quer dizer que o préconstruído, que se manifesta sintaticamente, não pode, no entanto, receber "tradução" sob a forma de proposições por exemplo. Ele é citado, implicitamente admitido, reconhecido como anterior, mas não existe discursivamente, e muito menos linguisticamente, como anterior. Dar-lhe uma existência material implica cometer um erro de paradigma: não se trata de uma noção elaborada no quadro de uma filosofia realista da linguagem (PAVEAU, 2013, p. 75).

A forma proposta por Paveau (2013) de compreender o préconstruídopodeser, deacordocomaautora,frutodaprópriaindeterminação que parece acompanhar a noção após o seu "enfraquecimento teórico". A partir de Collinot e Mazière (apud PAVEAU, 2013, p. 75), a autora sugere que Pêcheux (1997), ao definir o pré-construído como "o impensado 
v. 9 (3)

226-243

set-dez

2019

do pensamento", acabou por gerar duas implicações teóricas. Em primeiro lugar, está a dificuldade de trabalhar-se a partir de um outro não assinalável, o que pode inviabilizar a recuperação de traços pelo analista. Em segundo lugar, está o papel subalterno a que a noção ficou sujeita quando atrelada à concepção de interdiscurso, contribuindo para que, mais uma vez, fosse entendida como a presença do outro no discurso. Ao mesmo tempo, ressalta-se que o vigor da hipótese do préconstruído não se anula totalmente, uma vez que ele desempenha papel fundamental ao assegurar a evidência semântica que desencadeia certo regime de interpretação dos enunciados.

\section{Pré-discursos: novas possibilidades de análise?}

O corpus a ser apresentado é composto por enunciados produzidos por grupos de oposição à Dilma Rousseff durante os anos de 2015 e 2016, período posterior à sua reeleição e em que se verificam diversas manifestações cuja motivação era, entre outros pontos, apoiar o processo de impeachment da ex-presidente petista. Tais movimentos foram registrados em vídeo pelos próprios manifestantes ou por jornalistas de agências de notícia como IG, Folha de São Paulo, Estadão, O Globo, entre outros, e postados na rede social de compartilhamento de vídeos Youtube.

De acordo com Paveau (2013), identificamos indícios de prédiscursos que parecem evocar os vestígios de partilha semântica por meio das filiações discursivas (apelo aos precursores e nomes próprios); por organizadores textual-cognitivos (tipologia, metáfora e antítese); e, por último, por meio de mundos que se encontrariam partilhados entre os agentes humanos e não humanos (dêixis enciclopédica).

Devido à limitação de espaço, descreveremos brevemente o que Paveau (2013) entende por filiações discursivas e organizadores textual-cognitivos, enquanto reservaremos maior espaço à noção de mundos partilhados, pois esta última possibilita um melhor diálogo entre as noções apresentadas até o momento.

A noção de filiação discursiva é adotada por Paveau (2013, p. 159) como forma de apontar para o recurso argumentativo dos falantes que se baseia em recorrer a uma "espécie de número de lugares de memória, dotados de 'agentes de transmissão' que parecem pré-existir às produções discursivas individuais". Sinais de filiação discursiva podem ser identificados por meio do apelo aos precursores 
e da evocação de nomes próprios. Embora haja outras formas em que é possível observar os traços de filiações discursivas, limitar-nos-emos a esses dois, pois, nos enunciados extraídos durante as manifestações, identificamos a presença de materialidades discursivas que evocam a figura dos militares ("Hoje estamos sofrendo o que os militares evitaram em 1964. Isto não é um movimento golpista, só exercemos o direito de nos manifestar" - fala do deputado Eduardo Bolsonaro, durante manifestação na Avenida Paulista) e de nomes próprios de países que representariam o alinhamento à ideologia comunista ("Por que nosso dinheiro foi pra Cuba?" - fala de manifestante em apoio ao impeachment de Dilma, durante ato realizado na Avenida Paulista).

Nos enunciados em destaque, observa-se que a categoria militares e o nome próprio Cuba funcionam como filiações discursivas, de tal modo que, no primeiro exemplo, ressalta-se o laço patrimonial, em que a evocação ao grupo dos militares garante "a transmissão tanto do passado quanto da verdade" (PAVEAU, 2013, p. 159), o que permite "a construção de heranças coletivas do passado para um grupo, uma cultura, uma civilização" (PAVEAU, 2013, p. 175). Em Cuba, por sua vez, o nome próprio reforça a filiação discursiva dos opositores à ex-presidente petista, pois veicula, de uma só vez, conhecimentos enciclopédicos, estereótipos e ideológicos convocados pelos opositores ao PT e, ao mesmo tempo, rechaçados por esse mesmo grupo.

Deve-se destacar, ainda, no que se refere à evocação que os manifestantes fazem do apelo patrimonial por meio dos militares, como o caráter pré-discursivo desse enunciado em específico é sentido e corroborado pelos sujeitos que o empregam, pois, normalmente, manifesta-se sempre acompanhado da data de 1964. Esse período, caro aos adeptos de um governo militar, parece indicar o que Paveau (2013) classifica como "o mito do tempo de antes" (PAVEAU, 2013, p. 178) cujo caráter de enunciação patrimonial (PAVEAU, 2013) caminha rumo, também, como se vê no apelo aos precursores, à consolidação de heranças coletivas de um grupo dado, em que o passado é resgatado como símbolo de verdade por esse mesmo grupo.

Os organizadores textual-cognitivos são indícios de prédiscursos que se situam entre "a elaboração mental e a construção textual" (PAVEAU, 2013, p. 211). Em outras palavras, os organizadores textual-cognitivos são responsáveis por atuar de forma a auxiliar o sujeito a classificar aquilo que pensa. Tais organizadores podem se manifestar por meio da tipologia, da metáfora e da antítese. No corpus 
v. 9 (3) $226-243$ set-dez 2019

deste trabalho, os exemplos mais representativos de organizadores textual-cognitivos foram aqueles que envolviam a tipologia. Segundo Paveau (2013, p. 212), essa ferramenta cognitiva estrutura em grupos, ou listas mentais, "os objetos do mundo". As tipologias se subdividem em polêmicas e organizacionais. As primeiras são "ideologicamente orientadas" (designam julgamentos e opiniões, de forma mais manifesta), e a segunda seria responsável por administrar o argumento de forma a dividir os temas mencionados em grupos específicos.

Nas manifestações ocorridas após a reeleição de Dilma Rousseff, os indícios de tipologização polêmica ocorrem de forma significativa: "O povo não é besta. Vai para a Venezuela, vocês são o câncer. "Traidor da pátria, arruaceiro e vagabundo"; "Nosso foco sempre foi o PT, sempre foi o PT, porque é o partido que levou o Brasil de cabeça pra baixo, é o partido que infiltra terrorista, é o partido que tá vinculado ao PCC, é o partido que tá vinculado a tudo de podre que tem" (enunciados capturados em vídeo por jornalistas do IG em ato pró-impeachment na Av. Paulista).

Os enunciados traidor da pátria, arruaceiro e vagabundo e é o partido que infiltra terrorista, é o partido que tá vinculado a tudo de podre que tem denunciam um funcionamento discursivo-cognitivo muito próximo do processo de classificação humana, a qual ocorre, dentre outras formas, por meio da tipologia. Tal processo, de acordo com Paveau (2013, p. 212), é construído pelos sujeitos "a partir de temas variados que permitem aos sujeitos classificar e categorizar os objetos do mundo".

A autora argumenta que a tipologia é "uma forma textual de lista assintática" (PAVEAU, 2013, p. 212) que pode se concretizar de diferentes formas, sendo a mais representativa aquela próxima a uma lista lexical em que se opera "uma espécie de inventários de conceitos" (GOODY, 1979 [1977], p. 149 apud PAVEAU, 2013, p. 212).

Para a linguista, a tipologia evidencia tanto um aspecto prédiscursivo quanto a atuação de uma ferramenta da tecnologia discursiva ${ }^{1}$, uma vez que a forma de lista tanto resgata conhecimentos distribuídos por um grupo quanto mostra a organização destes em conformidade com os materiais (bloco de notas, lista de compras, entre outros) que auxiliam as atividades humanas mais diversas.

\footnotetext{
1 "Entendo por ferramentas da tecnologia discursiva as ferramentas cognitivas, noção proposta pela pesquisadora americana L. Resnick (cognitive tools). Trata-se de instrumentos materiais (uma base de dados ou uma agenda) ou não (para L. Vygotski, por exemplo, a ferramenta das ferramentas é a linguagem) que permitem pensar e categorizar" (PAVEAU, 2013, p. 145).
} 
Além disso, Paveau (2013) advoga que não se restringe aos seres e ao mundo a organização textual-cognitiva sob a forma tipológica, na verdade, por as tipologias polêmicas serem ideologicamente orientadas, sua dimensão cognitiva vê-se reforçada por também se organizarem assim as opiniões e os julgamentos.

Ainda que tenhamos exposto de forma introdutória os outros focos de análise que a noção de pré-discurso parece trazer à vertente francesa da Análise do Discurso, essa breve explanação serve para mostrar a especificidade da proposta de Paveau (2013), que busca aliar discurso e cognição. Diferentemente do que se verifica com a noção de pré-construído, a hipótese dos pré-discursos não se encontra ancorada ao nível sintático dos enunciados; trata-se, na verdade, de identificar, na produção discursiva imediata dos sujeitos, os indícios de enlaces semânticos que apontam para as anterioridades discursivas; em outras palavras, a atenção não recai sobre o mecanismo enunciativo em si, mas sobre "o dispositivo cultural que o torna possível" (PAVEAU, 2013, p. 178), o que acaba por ampliar a consideração em torno dos fatores que impactam a produção discursiva.

Porém, no que se refere aos indícios de pré-discursos que sugerem a existência de mundos partilhados - apesar da especificidade dos pré-discursos anteriormente assinalada -, é possível tecer análises que dialoguem tanto com o conceito de pré-construído quanto com a hipótese dos pré-discursos. A aproximação torna-se possível, pois, no que compete ao efeito de evidência e à universalidade, as duas formulações apresentam mais semelhanças do que contrastes.

Paveau (2013) argumenta ser necessário haver um mínimo de estabilidade do sentido (estabilidade intersubjetiva, em outras palavras) para que haja troca conversacional e para que os discursos sejam possíveis. Essa "comunidade do sentido" possibilita o adequado funcionamento cognitivo quando os sujeitos se encontram em interação com outros agentes humanos e com agentes não humanos (na teoria da cognição distribuída, os artefatos, como os blocos de notas, diários, entre outros, atuam de forma a permitir a partilha de conhecimento).

Os exemplos de pré-discursos que parecem residir nessa comunidade do sentido abarcam a dêixis enciclopédica marcada (são advérbios de tempo e lugar, pronomes demonstrativos, por exemplo, que convocam o acesso a uma "memória coletiva" pressuposta pelo locutor); a dêixis enciclopédica não marcada (apresenta as formas dêiticas habituais, mas não aponta para um contexto específico); as interrogações genéricas (são as frases interrogativas que generalizam e 
V. 9 (3)

$226-243$ set-dez 2019

pressupõem uma resposta previamente tomada como única possível); a declaração epistêmica (o sujeito acusa como fonte de saber um agente externo a ele por meio de construções do tipo "todo mundo sabe"); e a restrição epistêmica (um "imperativo categórico" manifestado por expressões como "forçoso constatar" e "deve-se admitir que").

No nosso corpus, contamos com um exemplo de dêixis enciclopédica marcada, conforme se verifica abaixo:

Eu tô aqui hoje, porque eu tô lutando pelo nosso país. Hoje, o mesmo se encontra destruído. Os três poderes tão corrompidos, e eu estou aqui reivindicando um direito como brasileiro, como povo. A gente sabe que o poder emana do povo. Estamos aqui pra defender essa parte, que é a nossa cidadania. O nosso país está prestes a receber um golpe comunista aí, e precisamos lutar contra isso. E a única forma que existe é clamar nossas forças armadas, como tá no artigo 142 e 144. Então precisamos de dar um basta nessa situação que estamos vivendo [manifestante em ato realizado em 16/08/2015 na Av. Atlântica].

De acordo com a teoria dos pré-discursos, no exemplo acima, o sujeito ativa a menção a um contexto que ele supõe também ser conhecido pelo seu interlocutor. Entretanto, não se trata, de acordo com Paveau (2013, p. 196), de uma referência que recuperaria meramente um tempo, um espaço ou uma pessoa. Na verdade, ele constrói uma referência que "parece ser do tipo conhecimento enciclopédico". Posto de outra forma, ao emergir a expressão "nessa situação que estamos vivendo", o que entra em jogo, segundo a perspectiva daqueles que se opuseram à Dilma Rousseff, seriam os problemas resultantes da corrupção, da suposta falta de moral política dos governantes e a provável incapacidade que estes apresentariam em pôr um fim às mazelas sociais que se verificam no país. No caso brasileiro, como isso parece se apresentar como um problema que perdura, a construção nessa situação que estamos vivendo evoca tanto o problema que por ora se impunha (a necessidade, na visão dos manifestantes, de pôr um fim à era PT), como elucida algo que eles já acreditam ter-se tornado epidêmico no país: a corrupção. Trata-se, portanto, de fazer referência a um arcabouço cultural e enciclopédico, o que reforça o efeito de evidência, a que o pré-discurso também se encontra sujeito, e o aspecto de universalidade. Nas palavras de Paveau:

[...] trata-se de um fenômeno de reforço da propriedade de transmissibilidade dos pré-discursos, sobre o eixo horizontal da comunicabilidade: os locutores insistem sobre a partilha dos saberes, estabelecendo essa partilha. O pré-discurso aqui é tanto alegado quanto instalado (PAVEAU, 2013, p. 197). 
Na perspectiva de Pêcheux (1997), poder-se-ia analisar, por meio da relativa determinativa "que estamos vivendo", os eixos complementares entre si que compõem o interdiscurso: o préconstruído e a articulação. Sob a ótica do teórico francês, teríamos que a subordinada relativa introduz o pré-construído, pois seu encadeamento sintático gera um efeito discursivo, em que a relativa constituiria um "sempre já-aí" e que, ao ser sintagmatizada na materialidade linguística, assinala o eixo da articulação. As dimensões que integram o interdiscurso acabam por providenciar o efeito de evidência próprio do funcionamento ideológico e indicam o "caráter universalmente partilhado do pré-construído" (PAVEAU, 2013, p. 74), fazendo, por isso, com que se aproxime, nesse ponto, do conceito de pré-discurso, pois este também possui "uma dimensão coletiva" (PAVEAU, 2013, p. 75).

Outras relações entre as duas teorias aqui abordadas podem ser estabelecidas a partir de um dos últimos textos de Pêcheux (apresentado em conferência), Discurso: Estrutura ou Acontecimento ([1983] 2002):

O sujeito pragmático - isto é, cada um de nós, os "simples particulares" face às diversas urgências de sua vida - tem por si mesmo uma imperiosa necessidade de homogeneidade lógica: isto se marca pela existência dessa multiplicidade de pequenos sistemas lógicos portáteis que vão da gestão cotidiana da existência (por exemplo, em nossa civilização, o porta-notas, as chaves, a agenda, os papéis etc.) até as "grandes decisões" da vida social e afetiva (eu decido fazer isto e não aquilo, de responder a x e não a y etc.) [...] Nesse espaço de necessidade equívoca, misturando coisas e pessoas, processos técnicos e decisões morais, modo de emprego e escolhas políticas, toda conversa (desde o simples pedido de informação até a discussão, o debate, o confronto) é suscetível de colocar em jogo uma bipolarização lógica das proposições enunciáveis (PÊCHEUX, 2002, p. 33).

Em Paveau (2013, p. 23), o postulado da intersubjetividade é uma das noções mobilizadas pela autora na delimitação da sua hipótese sobre os pré-discursos. Como a autora argumenta que esses últimos são, na verdade, quadros pré-discursivos coletivos, retoma a noção de intersubjetividade, integrando-a a sua teoria a partir da utilização semântica do termo, para refletir a respeito da apropriação que os sujeitos fazem de tais quadros: para a formação dos dados pré-discursivos, é necessário que os sujeitos compartilhem de conhecimentos de ordem cultural e histórica. Se, em Paveau (2013), a intersubjetividade é o que torna possível a existência dos pré-discursos, em Pêcheux, é a necessidade de homogeneidade lógica que leva à emergência de espaços discursivos que parecem responder a 
v. 9 (3)

226-243

set-dez 2019

uma suposta univocidade lógica. Sob a ótica da cognição distribuída, a homogeneidade lógica existiria em decorrência da necessidade do sujeito em classificar e categorizar o mundo imediato que o cerca, o que só seria possível em decorrência de os sujeitos compartilharem, conforme mencionado, esquemas mentais e arcabouços histórico-culturais.

Além disso, Pêcheux (2002) menciona o funcionamento de "pequenos sistemas lógicos portáteis" que reforçam a urgência dessa mesma homogeneidade lógica. Ainda sob a luz da cognição distribuída, conforme Paveau (2013, p. 146), a agenda, os blocos de notas, os papéis, entre outros, configuram ferramentas tecnológicas discursivas (as quais podem ser materiais ou não) sob as quais repousariam e se perpetuariam os pré-discursos. Em outras palavras, tais aparatos permitem a partilha semântica necessária para a evocação dos quadros pré-discursivos coletivos, permitindo também, com isso, que sejam traçados outros percursos de análise que considerem, por exemplo, modos de emergência dos pré-discursos a partir de organizadores textual-cognitivos.

\section{Considerações finais}

Neste artigo, perseguiu-se o objetivo de refletir sobre as relações de proximidade e de diferenciação entre a noção de préconstruído, já bem estabelecida no âmbito da Análise do Discurso de linha francesa, e a noção de pré-discursos, conforme a teorização relativamente mais recente de Marie-Anne Paveau. Tendo em vista que ambas as noções suscitam o tema das anterioridades discursivas, foi necessário, nas duas primeiras seções, apresentar as formulações teóricas que sustentam as duas noções para que, na terceira seção, a questão "novas possibilidades de análise?" pudesse ser, ao menos preliminarmente, respondida, considerando-se alguns exercícios de análise. Diante da exposição teórica e das análises empreendidas, podese afirmar, portanto, que dotar de uma dimensão cognitiva pontos já considerados na Análise de Discurso francesa parece demonstrar que a possibilidade de aproximação entre a $\mathrm{AD}$ e as ciências da cognição seja, talvez, não necessariamente um novo caminho (no sentido de romper com o funcionamento ideológico, por exemplo), mas uma forma de proporcionar desdobramentos a partir, inclusive, daquilo que já se trabalha no interior das disciplinas aqui envolvidas (assumindo-se que a ideologia interpela o sujeito, outra questão seria estudar o modo como essa "matéria-prima" é dada a ser "conhecida" pelo sujeito). 


\section{Referências}

ALTHUSSER, Louis. Ideologia e aparelhos ideológicos de estado. Lisboa: Presença, 1970.

HENRY, Paul. Constructions relatives et articulations discursives. Langages. n. 37. Paris, 1975.

HENRY, Paul. Construções relativas e articulações discursivas. Caderno de Estudos Linguísticos. Trad. João Wanderley Geraldi e Celene Cruz. n. 19. Campinas, 1990.

PAVEAU, Marie-Anne. Os pré-discursos: sentido, memória, cognição. Trad. Débora Massmann e Graciely Costa. Campinas: Pontes, 2013.

PÊCHEUX, Michel. Semântica e Discurso: uma crítica à afirmação do óbvio. Trad. Eni Orlandi. 3. ed. Campinas: Editora da Unicamp, 1997.

PÊCHEUX, Michel. O discurso: estrutura ou acontecimento. Trad. Eni Orlandi. 3. ed. Campinas: Pontes, 2002. 